\title{
Percepción de las mujeres en situación de dependencia química dentro de Mato Grosso, Brasil
}

\section{Perception of women in chemical dependency situation inside Mato Grosso, Brazil}

\section{Percepção de mulheres em situação de dependência química no interior de Mato Grosso, Brasil}

Vagner Ferreira do Nascimento ${ }^{1}$, Marciana Fernandes Moll $^{2}$, Alisséia Guimarães Lemes ${ }^{3}$, Juliana Fernandes Cabral ${ }^{4}$, Tayane Próspero Cardoso ${ }^{5}$, Margarita Antonia Villar Luis ${ }^{6}$

${ }^{1}$ Enfermeiro. Doutorando em Bioética. Professor Assistente da Universidade do Estado de Mato Grosso - UNEMAT, Tangará da Serra, Mato Grosso/BR. Endereço: Rua Moreira Cabral N475 Bairro Campinas CEP:78600-000 Cidade: Barra do Garças MT, Brasil.E-mail: vagnerschon@hotmail.com

${ }^{2}$ Enfermeira. Doutora em Enfermagem Psiquiátrica pela Universidade de São Paulo - EERP/USP, Ribeirão Preto, São Paulo/BR. E-mail:mrcna13@yahoo.com.br

${ }^{3}$ Enfermeira. Doutoranda em Enfermagem Psiquiátrica pela Universidade de São Paulo - EERP/USP. Professora Assistente da Universidade Federal de Mato Grosso-UFMT, Barra do Garças, Mato Grosso/BR. E-mail: alisseia@hotmail.com

${ }^{4}$ Enfermeira. Mestre em Saúde Coletiva pela Universidade Federal de Mato Grosso - UFMT. Professora Assistente da Universidade do Estado de Mato Grosso- UNEMAT, Tangará da Serra, Mato Grosso/BR. E-mail: ju_fcabral@hotmail.com

${ }^{5}$ Enfermeira. Graduada pela Universidade Federal de Mato Grosso-UFMT, Barra do Garças, Mato Grosso/BR. E-mail: tayanepc@hotmail.com

${ }^{6}$ Enfermeira. Doutora de Enfermagem. Professora Titular no Departamento de Enfermagem Psiquiátrica e Ciências Humanas da Escola de Enfermagem de Ribeirão Preto da Universidade de São Paulo - EERP/USP, Ribeirão Preto, São Paulo/BR. E-mail: margarit@eerp.usp.br.

Cómo citar este artículo en edición digital: Nascimento, V.F., Moll, M.F., Lemes, A.G., Cabral, J.F., Cardoso, T.P., \& Luis, M.A.V. (2017). Percepción de las mujeres en situación de dependencia química dentro de Mato Grosso, Brasil. Cultura de los Cuidados (Edición digital), 21(48). Recuperado de http://dx.doi.org/10.14198/cuid.2017.48.04

Correspondencia: Universidade do Estado de Mato Grosso (UNEMAT), Campus Universitário de Tangará da Serra, Departamento de Enfermagem. MT-358, Km 7 - Jardim Aeroporto, Tangará da Serra - MT, CEP 78300-000, Brasil. Correo electrónico: vagnerschon@hotmail.com Recibido: 10/01/2017; Aceptado: 25/03/2017

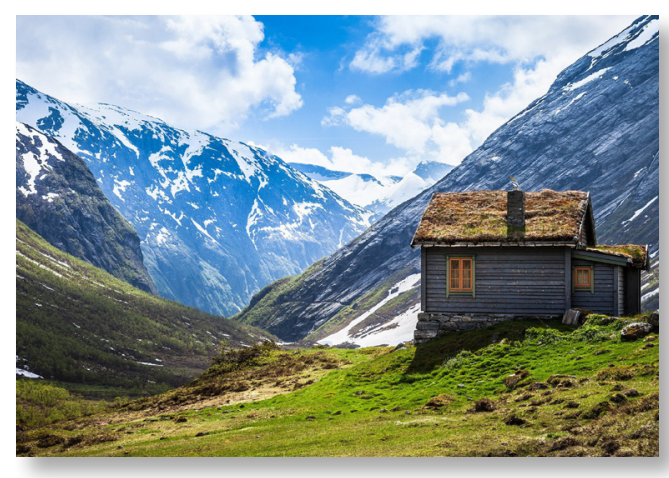

ABSTRACT

This study aimed to know the perception of women in chemical dependency situation within Mato Grosso. This is a descriptive and exploratory qualitative study, based on the theory of Peplau. Held in the only female therapeutic community, belonging to the Northeast of Mato Grosso - Brazil, in the period March-April 2016, with 15 women. Data collection occurred in the service itself, using semistructured interviews with writing and recording. For analysis, we used the Content Analysis. The results revealed that women in treatment in this community have similar drug-related experiences but tend to respond differently to treatment, especially since not all women have chemical dependency as their primary reason for being in that care facility. It 
is concluded that the therapeutic communities should strive to recognize the weaknesses presented by the women since the reception to develop therapeutic plans based on the potential of women. To do so, these services must value the multiple needs of these women, so that by providing them, greater possibilities of recovery can be made possible.

Keyword: Substance-related disorders, life change events, therapeutic community, women's Health.

\section{RESUMEN}

Este estudio tuvo como objetivo conocer la percepción de las mujeres en situación de dependencia química dentro de Mato Grosso. Se trata de un estudio cualitativo descriptivo y exploratório, basado en la teoría de Peplau. Celebrada en la única comunidad terapéutica femenino, perteneciente al noreste de Mato Grosso - Brasil, en el período marzo-abril de 2016, con 15 mujeres. La recolección de datos se produjo en el propio servicio, con entrevistas semiestructuradas con la escritura y la grabación. Para el análisis, se utilizó el análisis de contenido. Los resultados mostraron que las mujeres tratadas en esta comunidad, tienen experiencias similares relacionadas con las drogas, pero tienden a responder de manera diferente al tratamiento, sobre todo porque no todos tienen la adicción como la razón principal para estar en este host de servicio. Se concluye que las comunidades terapéuticas deben tratar de reconocer las debilidades mostradas por las mujeres de la sede de los planes de tratamiento guiadas en las capacidades de las mujeres están desarrollados. Por lo tanto, estos servicios deben mejorar las múltiples necesidades de estas mujeres, por lo que para cumplir con ellas se pueden hacer posible una mayor posibilidad de recuperación.
Palabras clave: Trastornos Relacionados con Sustancias, acontecimientos que cambian la vida, comunidade terapéutica, salud de la mujer.

\section{RESUMO}

Objetivou conhecer a percepção de mulheres em situação de dependência química no interior de Mato Grosso. Trata-se de estudo descritivo-exploratório, qualitativo, fundamentado na Teoria de Peplau. Realizado na única comunidade terapêutica feminina, pertencente a Região Nordeste Matogrossense - Brasil, no período de março a abril de 2016, com 15 mulheres. A coleta de dados ocorreu no próprio serviço, utilizando entrevista semiestruturada com roteiro e gravação. Para análise, utilizouse a Análise de Conteúdo. Os resultados revelaram que as mulheres em tratamento nessa comunidade, possuem experiências semelhantes ligadas às drogas, mas tendem a responder de forma distinta ao tratamento, principalmente por que nem todas possuem a dependência química como principal motivo para estarem nesse serviço de acolhimento. Conclui-se que as comunidades terapêuticas devem se empenhar no reconhecimento das fragilidades apresentadas pelas mulheres desde o acolhimento para que sejam elaborados planos terapêuticos pautados nas potencialidades das mulheres. Para tanto, esses serviços devem valorizar as múltiplas necessidades dessas mulheres, para que ao supri-las possam ser viabilizadas maiores possibilidades de recuperação.

Palavras-chave: Transtornos relacionados ao uso de substâncias, acontecimentos que mudam a vida, comunidade terapêutica, saúde da mulher. 


\section{INTRODUÇÃO}

No mundo, estima-se que um total de 246 milhões de pessoas tenha feito uso de drogas ilícitas em 2013 e cerca de 27 milhões mantém uso problemático delas (Unodc, 2015). O panorama atual com o aumento de consumo, abuso e dependência do álcool, principalmente pelas mulheres, bem como suas possíveis consequências constituem um problema que merece atenção e implica a necessidade de se obter mais conhecimento acerca deste universo feminino (Assis \& Castro, 2010).

Para tanto, há duas faces importantes a serem analisadas com relação a imagem da mulher. Enquanto não dependente química o seu papel social se desenvolve entre os estigmas da maternidade, fragilidade, recato, fidelidade, entre tantos outros, mas esse papel se modifica quando a dependência química é percebida pela sociedade, incluindo aqui o seu espaço familiar, que passa a julgá-la como irresponsável, promíscua, amoral, incapaz de cuidar da família e dos filhos (Leal, 2009).

E devido ao efeito das drogas acontecerem de uma forma mais lenta, as mulheres possuem uma predisposição maior em relação aos prejuízos causados pelo consumo. Também costumam abandonar o tratamento antes do término, o que pode justificar o número ínfimo de mulheres nos centros de tratamento (Azevedo \& Silva, 2013).

De maneira geral, o estigma social vivenciado pela mulher que faz uso de drogas impõe obstáculos que dificultam a procura espontânea pelos serviços especializados e isso contribui para que tanto as estatísticas como os estudos foquem somente no coletivo masculino (Bolzan, 2015).

Assim, essas mulheres necessitam de profissionais que se disponham a compreendê- las em seu sofrimento, e não apenas que lhes oferecessem abordagens diagnósticas e/ou farmacológicas e não valorizem as particularidades de suas dores (Nobrega \& Oliveira, 2005).

Contudo, a direção de políticas públicas em algumas localidades também pode velar os direitos da mulher, como por exemplo, no estado brasileiro de Mato Grosso, onde as políticas que incorporam a transversalidade de gênero são focalizadas e orientadas para a inclusão de coletivos em situação de vulnerabilidade social, não havendo um reconhecimento explícito de que essa situação é crescente entre as mulheres (Pereira, Silva, Ciriaco, \& Rambla, 2010).

Nessa perspectiva, faz-se necessário fomentar a compreensão dos gestores, profissionais e sociedade sobre as particularidades que revestem as vivências das mulheres, em especial àquelas que estão em situação de dependência química. Além disso, o respeito aos direitos e a integralidade dessas mulheres deve direcionar as atitudes dos profissionais, principalmente se o tratamento da dependência química não for a prioridade imediata, mesmo estando num espaço terapêutico para esse fim.

Em razão disso, a necessidade de espaços que propiciem a liberdade, escuta ativa, autonomia, bem como a inserção da mulher em situação de dependência na terapêutica em saúde mental, por si só, justificam a importância de se conhecer as histórias de vida dessas mulheres, em particular durante seu tratamento (Fertig, Schneider, Oliveira, Olschowsky, Cmatta, \& Pinho, 2016).

Ademais, conhecer as especificidades de pessoas que usam drogas em seus contextos de vida, instrumentaliza o enfermeiro e a equipe multiprofissional na produção de estratégias 
de cuidado, ampliando a efetividades dos planos terapêuticos (Souza, Oliveira, Chagas, \& Carvalho, 2016).

Dessa forma, esta investigação busca responder ao seguinte questionamento: Como as mulheres em situação de dependência química se percebem? Respostas advindas desta questão podem possibilitar o desvelar de saberes norteadores de práticas voltadas para as singularidades dessas mulheres, bem como direcionar abordagens terapêuticas coerentes aos propósitos da Rede de Atenção Psicossocial (RAPS). Com isso, o estudo objetivou conhecer a percepção de mulheres em situação de dependência química no interior de Mato Grosso.

\section{MÉTODOS}

Esse estudo compõe a pesquisa intitulada saúde mental: uma abordagem com profissionais de saúde, estudantes, usuários e familiares, cuja aprovação se deu pelo protocolo $\mathrm{n}^{\circ} 515705$, emitido pelo Comitê de Ética em Pesquisa, da Universidade Federal de Mato Grosso (UFMT) que considerou os aspectos éticos de pesquisas com seres humanos preconizados na Resolução 466/2012 do Conselho Nacional de Saúde.

Trata-se de um estudo do tipo descritivoexploratório, com abordagem qualitativa. Segundo Minayo (2011) a pesquisa qualitativa responde questões particulares, trabalha com significados, motivos, aspirações, das crenças, valores e atitudes. O ser humano é entendido como parte da realidade social, não somente no agir, mais o pensar sobre suas ações e a realidade vivida e partilhada com seus semelhantes.

$\mathrm{O}$ estudo fundamentou-se na Teoria de Peplau, a qual objetiva o cuidado humano centrado no processo interpessoal entre enfermeiro e cliente. A utilização dessa Teoria, deve-se a consideração que o dependente químico é um cliente que demanda intenso esforço próprio na busca da recuperação e prevenção da recaída à drogas, e a enfermagem deve estabelecer vínculos e atuar no sentido de fortalecer esse cliente, auxiliando-o a moverse em direção ao pleno desenvolvimento de seu potencial (Moraes, Lopes, \& Braga, 2006).

$\mathrm{O}$ estudo foi realizado em uma Comunidade Terapêutica (CT) feminina urbana de um município do interior de Mato Grosso, com capacidade máxima de trinta usuárias. A escolha desse local deuse por constituir-se na única CT feminina compreendida na mesorregião do nordeste matogrossense (fronteira com os estados de Goiás-GO, Tocantins-TO e Pará-PA) abrangendo 25 municípios, com uma área geográfica de $177.336,73 \mathrm{~km}^{2}$ e com população de 376.332 habitantes em 2010 (Brasil, 2010).

Trata-se de uma CT com caráter provisório, religioso e filantrópico, desenvolvendo cuidados exclusivos a mulheres maiores de 18 anos, em condições clínicas estáveis, com problemas associados ao uso nocivo ou dependência de substância psicoativa. Realiza acolhimento de pessoas, de forma voluntária, por demanda espontânea, judicial ou encaminhadas por outros serviços. Possui ambiente residencial com tratamento médio de nove meses. Sua equipe de profissionais é composta por religiosos sem formação específica e colaboradores voluntários.

A população do estudo foi formada por 15 mulheres em recuperação, as quais atenderam aos seguintes critérios de inclusão: estarem em tratamento há, no mínimo, trinta dias; terem idade entre 18 anos ou mais e aceitarem participar desse estudo, assinando o Termo de Consentimento Livre e Esclarecido (TCLE). 


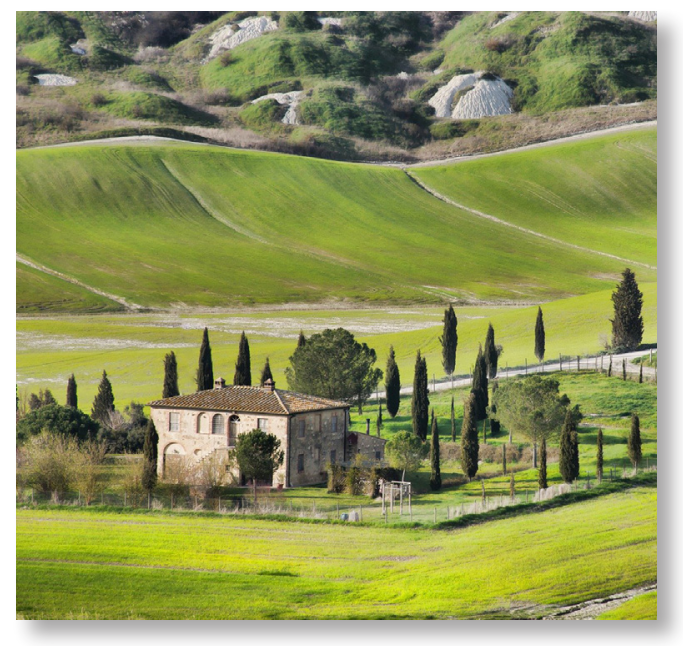

Previu-se a exclusão daquelas com agravos que dificultassem sua participação no estudo (o que não ocorreu).

Durante o processo de coleta dos dados que esse quantitativo (15 participantes) foi considerado suficiente, com base na exaustividade das informações de interesse, tal como proposto pela saturação amostral (Fontanella et al., 2011). Considerando a importância de se manter o anonimato das participantes, as mesmas foram identificadas pela codificação do tipo alfanumérica, de modo que a letra $\mathrm{M}$ indica mulher, e o elemento numérico sequencial as caracterizou.

A coleta de dados foi realizada através de entrevistas semiestruturadas, as quais duraram em média de 45 minutos e ocorreram durante os meses de março a abril de 2016, na própria comunidade terapêutica. Tais entrevistas foram norteadas por um roteiro e aconteceram individualmente no consultório de enfermagem da CT, por constituir um espaço iluminado, arejado e reservado, o que favoreceu a harmonia e o bem-estar da participante. Para não comprometer as atividades terapêuticas da instituição, as entrevistas foram agendadas previamente junto a direção do serviço.
As respostas das participantes foram gravadas em gravador digital, após o consentimento prévio de cada uma delas e após foram transcritas na íntegra. Para a análise dos dados utilizou-se a Análise de Conteúdo (AC) que interpreta o conteúdo, após leitura detalhada, o que permite o alcance do conhecimento de aspectos e fenômenos da vida social. As linhas de análise foram delimitadas a partir de pré-análise, exploração do material, tratamento dos resultados, inferência e interpretação (Gil, 2010).

\section{RESULTADOS E DISCUSSÃO}

A partir dos achados do estudo, verificou-se predomínio de mulheres na faixa etária entre 21 e 30 anos, de cor parda, protestantes evangélicas, solteiras, com ensino fundamental incompleto, com renda mensal de até um salário mínimo, anterior ao tratamento trabalhando como babá e doméstica, morando com filhos e cônjuge masculino desempregado.

$\mathrm{A}$ iniciação às drogas ocorreu entre 12 e 20 anos, por amigos, em festas, por meio da experimentação de bebidas alcoólicas e cigarro. Entre 31 e 40 anos se consideraram dependentes dessas substâncias, com frequência de uso diário. Entre as drogas ilícitas, destacaram maconha e cocaína, e ao avaliar o uso concomitante de drogas, prevaleceu cocaína com cigarro.

\section{A mulher no mundo das drogas}

Para enxergar a mulher em um cenário percebido ainda por muitos como predominantemente masculino, exige a remoção de vendas culturais que ocultam uma problemática histórica e velada. Ser do gênero feminino não significa fragilidade, mas predispõe a receios, medos e estigmas 
que vulnerabilizam recursos individuais e dificultam atitudes positivas diante dos vários enfrentamentos colocados nesse trajeto de resistência e/ou entrega.

Diante dessa perspectiva, as participantes desta investigação demonstraram uma condição de subserviência em função da dependência, como observado nas narrativas que se seguem. "É horrível por que a gente fica dependente fácil das drogas. A gente fica dependente de muitas outras coisas, principalmente quando a gente não trabalha né, por que ai a pessoa tem que arrumar um jeito pra ganhar dinheiro [...]. Fica arrumando um jeito para viver e manter aquele vicio, então é difícil! Entramos muitas vezes na criminalidade, deixo de ser quem eu sou de verdade [...]. (M3)". "É triste e muito difícil sendo mulher. E sair desse mundo[...] como parar de usar é mais difícil ainda ne. (M6)". "Acho que é uma dependente [...] existe alguns medos [...], você não vê como mudar, falta coragem [...]. (M9)". "A mulher nesse mundo é mais uma! não vê o caminho do certo, só o errado, ela está perdida. (M10)".

As narrativas anteriormente descritas demonstram que essas mulheres desenvolveram comportamentos negativos, os quais elas reconhecem, mas não evidenciavam outras motivações além da dependência química. Essa realidade as faziam perder o sentido da vida e se apresentarem desprotegidas, inseguras e ocultas.

Alguns estudos revelam, que a impotência da mulher nesse cenário é percebida especialmente quando ela se vê menos importante nos seus espaços sociais ou se torna um objeto da dependência, o que consequentemente pode intensificar conflitos em dimensões importantes de sua vida, tais como: autoimagem, valores pessoais e feminilidade (Vieira, Carvalho, Azevedo, Silva, \& Filha, 2010; Medeiros, Maciel, Sousa, Tenório-Souza, \& Dias, 2013).

Além disso, a história de vida, vulnerabilidades individuais e o contexto de vida dessas mulheres podem contribuir para a dependência química, bem como significa, na percepção delas, um aprisionamento definitivo ao consumo das drogas. Essa resignação perturba as funções cognitivas, compromete a saúde mental e desestrutura a condição do ser mulher (Wright, Gliksman, Khenti, \& Furegato, 2009; Unodc, 2015).

Não bastando os danos individuais, o envolvimento com as drogas pode levar a situações de criminalidade e marginalização (Chalub \& Telles, 2006). E, alguns estudos evidenciam que os usuários, principalmente mulheres expressam o medo de sofrer violência, seja pelo contato com o tráfico, brigas policiais e punição pela Lei, o que contribui para o desenvolvimento de uma consciência crítica e o reconheci $\neg$ mento da necessidade de mudança, motivando-as a busca pelo tratamento. Essa busca apoiase na tentativa de saírem do meio ambiente onde vivem, por perderem o sentido e o valor de pertencimento (Gomes, Ribeiro, Mattias, Brêda, \& Mângia, 2015; Ferreira, Borba, Capistrano, Czarnobay, \& Maf $\neg$ tum, 2015).

Outras mulheres neste estudo, enfatizaram essa perda de valores, acrescido das mudanças de papéis sociais vivenciadas por elas, após o envolvimento com as drogas. "Ela não é nada, um ser sem valor. (M2)". "É diferente sei lá, é uma coisa que só traz mal. As drogas destroem a vida da mulher. Perdemos o direito de ser mãe, é um vício que traz muito mal. (M4)”. "Muito ruim. Todo mundo você perde, perde amizades, seus valores, perde a confiança em si mesma, perde tudo. (M7)”. “[...] Perde 
integridade própria de cidadã brasileira. (M13)".

A desagregação familiar é o principal problema dentre os usuários de drogas, uma vez que após o início do uso de drogas, pode ocorrer conflitos e perdas de vínculos e alguns familiares começam a se afastar e desconsiderar as relações e laços de afeto construídos. Esse comportamento do meio social, reforça a sensação de marginalidade advinda da dependência química e, ainda, de perdas físicas, materiais e, principalmente, morais (Alvarez, Gomes, \& Xavier, 2014).

Em alguns casos, a questão de gênero foi colocada como facilitador ao acesso às drogas, sendo que a mulher fez valer do seu corpo como moeda de troca. "Já me ofereceram droga se eu fosse para atrás do muro [...]. É horrível sentir-se um pedaço qualquer. (M5)”. "Cruel e terrível, aconteceu uma vez da pessoa vir com um pedacinho bem pequenininho e só me daria se eu ficasse com ele, falei pega sua droga e vai embora, você acha que isso faz alguma diferença para mim, eu não quero [...]. Todas as vezes que eu queria eu conseguia trabalhando, fazia unha, pegava meu dinheiro e fumava [...]. (M8)”. “[...] muitos não querem usar camisinha, meio que força você, daí você acaba aceitando. (M2)".

Estudos apontam que estes fatos narrados, muitas vezes velados é uma prática comum para a aquisição das drogas. Essa realidade faz com que as mulheres percam seus valores éticos e morais e isso as fazem negar sua condição patológica. Dessa maneira, optam impulsivamente pela aquisição da droga a fim de obter recompensas imediatas, mesmo sob o risco de consequências negativas (Menezes \& Gesser, 2012).

Somado a isso, a violação desse corpo pela multiplicidade e grande rotatividade de parceiros sexuais predispõe a mulher ao risco de contrair infecções sexualmente transmissíveis e acelerar seu adoecimento físico e psicoemocional (Timpson, Williams, Bowen, Atkinson, \& Ross, 2010; Corsi, Rinehart, Kwiatkowski, \& Booth, 2010).

As relações de poder estabelecidas nesse universo às mulheres, tornam-se ainda mais evidentes com a disparidade entre os gêneros, que tende a ampliar essas desigualdades que as deixam mais vulneráveis ao olhar dos outros. "[...] A mulher no mundo das drogas, não devia ter a mesma facilidade do que os homens [...]. Ela sofre muito com a sociedade [...]. (M1)".

Como observado nesta narrativa, a própria mulher reproduz a cultura permissiva às drogas para os homens. Compreensão que acentua o distanciamento entre os gêneros e determina proteção somente para a mulher, o que intensifica estereótipos que a torna mais marginalizada e invisível em participação na sociedade.

\section{A busca pelo tratamento na comunidade terapêutica}

A procura por ajuda entre as mulheres em uso e/ou abuso de drogas tende a ser tardia e neste estudo, algumas buscaram ajuda após refletirem sobre sua condição atual, o que as levaram a se culparem pelos seus atos. "O motivo foi justamente o uso da droga que fiz e ter direcionado para uma vida que não favorecia, me prejudicava. (M1)". "Foi as palavras desse amigo meu que te falei. Porque eu estava num período decadente, de muita tristeza, estava fumando mais e eu não estava ficando legal, [...] passava semanas drogada. (M2)". "Minha situação [...] mexendo com coisas erradas e sozinha. (M11)". "Assim, na verdade foi medo de terminar como outras 
pessoas debaixo da ponte, e eu não queria isso pra minha vida [...]. Toda vida fui uma mulher que trabalhava, tinha uma vida muito boa, um dia fiz a bobeira de colocar um trem desse na boca [...]. Ai eu mesmo vim, eu mesmo liguei, eu mesmo fiz tudo, não tive ajuda de ninguém. Mas, [...] foi uma amiga minha que me deu o número do telefone [...]. (M8)". "Não querer ir para rua e ser uma "noiada" igual elas [...]. (M10)". "Fico mais doente vendo [...] sei o que é esse mundinho [...]. (M14)".

Como apontado pelas mulheres, as motivações pela busca por atendimento se deram pelas singularidades resultantes da dependência química, as quais desencadearam a diminuição da qualidade de vida e por conseguintes vivências desagradáveis no cotidiano.

Um estudo realizado na região sul do Brasil, evidenciou que na consciência do fracasso, no confronto entre o que se quer e o que não quer, é que parece surgir a compreensão do possível, de um projeto construtivo viável de vida longe das drogas (Rigotto \& Gomes, 2002).

Segundo a literatura, as perdas materiais, físicas e familiares, as comorbidades e o reconhecimento da impotência são perturbadores que também mobilizam a mulher, por vezes sem noção profunda do que está havendo a alcançar os serviços de acolhimento (Carvalho, Brusamarello, Guimarães, Paes, \& Maftum, 2011).

Para as mulheres, muitos são os eventos e/ou elementos desencadeadores da busca pelo tratamento, porém parece que o adoecer psíquico, acrescido da preocupação de amigos e familiares vem ocupando importante espaço nesse processo decisório (Assis \& Castro, 2010).

Entre outras integrantes deste estudo, a participação da família na evidenciação da situação de saúde dessas mulheres juntamente com o afeto e a preocupação com os filhos foram "disparadores" para a busca pelo tratamento. "Minha família, meus filhos [...]. Primeiro minha mãe conversou muito comigo, no começo eu não quis escutá-la, de jeito nenhum não quis nem saber, mas depois eu fui vendo com o passar do tempo que eu estava deixando minha casa abandonada, deixando meus filhos de lado, e meus filhos pra mim é tudo [...]. (M3)". "Porque eu não estava me sentido bem, [...] eu tive muitos danos, danos de ter perdido meus filhos e meus bens, estar solitária, vazia. (M4)”. "Eu bebia e só fazia coisa errada. Meus parentes perceberam e disseram você tem que se cuidar, daí você vai se quiser. (M6)". "Porque eu sentia vergonha, vergonha do meu filho, minha família sempre precisava de mim. Precisava de eu cuidar dos meus netinhos, e quando iam passear lá em casa, ficava pensando como que eu vou fazer com a droga [...]. (M7)".

A família tende a ter uma expectativa positiva em relação a recuperação e por isso consegue ajudar o dependente na superação de sua dependência por meio de diferentes mecanismos, tais como: busca pelo tratamento à abstinência, utilizando de muito diálogo; oferta de ajuda externa e direcionamento para grupos de apoio (Xavier, Rodrigues, \& Silva, 2014).

Considerando que a mulher, muitas vezes não possui resistência em manter-se no tratamento, o papel da família é fundamental no sentido de apoiá-la, evitando observações críticas, hostilidade e excessivo envolvimento emocional que aumenta as chances de recaída (Oliveira \& Mendonça, 2012).

Diferentemente, algumas mulheres recorreram as comunidades primeiramente na tentativa de serem premiadas com um lar, 
um espaço protegido, seguro e solidário. "Uma casa para morar, pois nem serviço eu tinha. Foi a única porta que abriu para mim. (M2)”. "Eu acho que precisava de local seguro para cuidar de mim, [...] eu precisava de uma casa agora [...]. (M5)". "Só mesmo um lugar para ficar [...]. Não estar sozinha para me reerguer [...]. (M10)".

Nas narrativas, as mulheres pensam na CT como uma alternativa de moradia. No entanto, na literatura existem críticas ao modelo dessas ambiências, pois retoma a discussão do modelo de internamento/institucionalização, que vai na contramão dos serviços substitutivos, fazendo imperar a lógica manicomial (Pacheco \& Scisleski, 2013).

Muitas vezes, quem adentra uma CT, tem outras motivações, além do desejo de abandonar as drogas e isso deve ser valorizado pela equipe no momento do acolhimento. Nessa perspectiva a CT pode representar a oportunidade de resgate de cidadania das pessoas, além de emancipar as mulheres para reconquistarem seus sonhos e avançarem (Damas, 2013).

\section{CONSIDERAÇÕES FINAIS}

A partir do estudo, verificou que as mulheres em tratamento nessa CT, possuem experiências semelhantes ligadas às drogas, mas tendem a responder de forma distinta ao tratamento, principalmente por que nem todas possuem a dependência química como principal motivo para estarem nesse serviço de acolhimento.

Destaca-seainda, que mesmo considerando as particularidades dessas mulheres, existem sofrimentos comuns, destacando tristeza, solidão e conflitos de papéis, com ênfase para o papel de mulher-mãe, o qual se acentuou pela separação da família ao iniciar o tratamento.

Diante dessa realidade, as CT devem se empenhar no reconhecimento das fragilidades apresentadas pelas mulheres desde $\mathbf{o}$ acolhimento para que sejam elaborados planos terapêuticos pautados nas potencialidades das mulheres. Para tanto, esses serviços devem valorizar as múltiplas necessidades dessas mulheres, para que ao supri-las possam ser viabilizadas maiores possibilidades de recuperação.

\section{REFERÊNCIAS}

- United Nations Office on Drugs and Crime, (2015). Escritório das Nações Unidas sobre Drogas e Crime. Re-cuperado em 5 janeiro, 2016 da web site: http:// www. unodc.org/wdr2015.

- Assis, D. F. F., \& Castro, N. T. (2010). Alcoolismo Feminino: início do beber alcoólico e busca por tratamento. Textos \& Contexto, 9(2), 358-370.

- Leal, M. B. R. (2009). Ser mulher e dependente química: adesão ou adaptação ao tratamento? Brasilia: Universidade de Brasília.

- Azevedo, C. S., \& Silva, R. S. (2013). A importância da fa-mília no tratamento do dependente químico. Encontro: Revista de Psicologia, 16(25), 151-162.

- Bolzan, L. M. (2015). Onde estão as mulheres? A homogeneização da atenção à saúde da mulher que faz uso de drogas. Dissertação de mestrado, Pontifícia Universidade Católica do Rio Grande do Sul, Porto Alegre, Brasil.

- Nóbrega, M. P. S. S., \& Oliveira, E. M.. (2005).

Mulheres usuárias de álcool: análise qualitativa. Revista de Saúde Pública, 39(5), 816-823.

- Pereira, R. S., Silva, K. P., Ciriaco, C. D., \& Rambla, X. (2010). Transversalidade de gênero e políticas sociais no orçamento do estado de Mato Grosso. Revista Estudos Feministas, 18(2), 425-450.

- Fertig, A., Schneider, J. F., Oliveira, G. C., Olschowsky, A., Camatta, M. W., \& Pinho, L. B. (2016). Mulheres usuárias de crack: conhecendo suas histórias de vida. Esc Anna Nery, 20(2), 310-316.

- Souza M.R.R., Oliveira J.F, Chagas M.C.G, \& Carvalho ESS. (2016). Gênero, violência e viver na rua: vivências de mulheres que fazem uso problemático de drogas. Rev Gaúcha Enferm, 37(3), e59876.

- Minayo, M. C. S. (2011). Pesquisa social: teoria, método e criatividade. Petrópolis: Vozes.

- Moraes, L. M. P., Lopes, M. V. O., \& Braga, V. A. B. (2006). Componentes funcionais da teoria de Peplau e sua confluência com o referencial de grupo. Acta paul. Enferm. 19(2), 228-233.

- Brasil. (2010). Instituto Brasileiro de Geografia e Estatística - IBGE. Censo demográfico do Brasil. Brasília: IBGE.

- Fontanella, B. J. B., Luchesi, B. M., Saidel, M. G. B., Ricas, J., Turato, E. R., \& Melo, D. G. (2011). 
Amostragem em pesquisas qualitativas: proposta de procedimentos para constatar saturação teórica. Cadernos de Saúde Pública, 27(2), 388-394.

- Gil, A. C. (2010). Como elaborar projetos de pesquisa. São Paulo: Atlas.

- Vieira, J. K. S., Carvalho, R. N., Azevedo, E. B., Silva, P. M. C., \& Filha, Ma.O.F. Maria de Oliveira Ferreira. (2010). Concepção sobre drogas: relatos dos usuários do CAPS-ad, de Campina Grande, PB. SMAD. Revista eletrônica saúde mental álcool e drogas, 6(2), 274-295.

- Medeiros, K. T., Maciel, S. C., Sousa, P. F., Tenório-Souza, F. M., \& Dias, C. C. V. (2013). Representações sociais do uso e abuso de drogas entre familiares de usuários. Psicologia em Estudo, 18(2), 269-279.

- Wright, M. G. M., Gliksman, L., Khenti, A., \& Furegato, A. R. F. (2009). A pesquisa sobre o fenômeno das drogas na perspectiva dos estudos multicêntricos na América Latina e Caribe. Revista Latino-Americana de Enfermagem, 17(spe), 759-761.

- Chalub, M., \& Telles, L. E. B. (2006). Álcool, drogas e crime. Rev Bras Psiquiatria, 28(Suppl. 2), s69-s73.

- Gomes, R. R., Ribeiro, M. C., Mattias, E. C., Brêda, M. Z., \& Mângia, E. F. (2015). Motivações e expectativas na busca de tratamento para o uso. Rev Ter Ocup Univ São Paulo, 26(3), 326-35.

- Ferreira, A. C. Z., Borba, L. O., Capistrano, F. C., Czarnobay, J., \& Maftum, M. A. (2015). Fatores que interferem na adesão ao tratamento de dependência química: percepção de profissionais de saúde. Rev Min Enferm, 19(2), 150-6.

- Alvarez, S. Q., Gomes, G. C., \& Xavier, D. M. (2014). Causas da dependência química e suas consequências para o usuário e a família. Rev enferm UFPE, 8(3), 641-8.

- Menezes, J. B., \& Gesser, W. P. (2012). A autonomia pri- vada do paciente dependente de substância no brasil e a discussão sobre a internação involuntária. Revista do Direito UNISC, 38, 95-112.

- Timpson, S. C., Williams M. L., Bowen, A. M., Atkinson, J. S., \& Ross M. W. (2010). Sexual Activity in HIV-Positive African American Crack Cocaine Smokers. Arch Sex Behav, 39(6), 6.

- Corsi, K. F., Rinehart, D. J., Kwiatkowski, C. F., \& Booth, R. E. (2010). Case Management Outcomes for Women Who Use Crack. J Evid Based Soc Work, 7(1), 30-40.

- Rigotto, S. D., \& Gomes, W. B. (2002). Contextos de abstinência e de recaída na recuperação da dependência química. Psic: Teor e Pesq, 18(1), 95-106.

- Carvalho, F. R. M., Brusamarello, T., Guimarães, A. N., Paes, M. R., \& Maftum, M. A. (2011). Causas de recaída e de busca por tratamento referidas por dependentes químicos em uma unidade de reabilitação. Colombia Médica, 42(2), 57-62.

- Assis, D. F. F., \& Castro, N. T. (2010). Alcoolismo Feminino: início do beber alcoólico e busca por tratamento. Textos \& Contextos (Porto Alegre), 9(2), 358-370.

- Xavier, M. F., Rodrigues, P. H., \& Silva, M. C. R. (2014). A percepção da família no tratamento e suporte de dependentes químico. Encontro Revista de Psicologia, 17(26), 99-110.

- Oliveira, E. B., \& Mendonça, J. L. S. (2012). Familiar com dependência química e consequente sobrecarga sofrida pela família: pesquisa descritiva. Online Brazilian Journal of Nursing, 11(1),14-24.

- Pacheco, A. L., \& Scisleski, A. (2013). Vivências em uma comunidade terapêutica. Rev Psicol Saúde, 5(2), 165-173.

- Damas, F. B. (2013). Comunidades Terapêuticas no Brasil: expansão, institucionalização e relevância social. Rev. Saúde Públ, 6(1), 50-65. 